HRJ

v.2 n.9 (2021)

Recebido: 04/01/2021

Aceito: 06/02/2021

\title{
A COVID-19 na Atenção Primária à Saúde: mais um desafio
}

Rafael Cardinali Rodrigues ${ }^{1}$

Danielle Jardim Mendonça Cardinali ${ }^{2}$

${ }^{1}$ Farmacêutico do Programa de Residência Multiprofissional em Saúde da Família e Comunidade/ ESCS/SESDF

${ }^{2}$ Fisioterapeuta do Núcleo de Reabilitação e Atenção Domiciliar/ SESDF

\section{RESUMO}

Em 2020 o mundo teve uma nova experiência há muito não vivida pela sociedade, uma pandemia sem precedentes. Em março desse ano a Organização Mundial de Saúde (OMS) declarou que a doença causada pelo novo coronavírus (Sars-Cov2), a COVID-19, estava presente em várias partes do mundo. Diante desse cenário e da ausência de tratamentos para essa doença, os governos adotaram medidas drásticas para o enfrentamento deste vírus, dentre elas, estratégias de distanciamento social, como o lockdown, para conter a velocidade de disseminação deste agente, o que causou profundas mudanças na sociedade. Apesar do grande potencial de transmissão, cerca de $80 \%$ dos casos são considerados leves e não utilizam serviços especializados sendo assistidos pelos serviços primários. Contudo, a maioria dos países utilizou, como estratégia de combate à doença, o fortalecimento dos níveis hospitalares. Diante deste paradoxo, é importante refletir que para um sistema de saúde desempenhar seu papel de prover saúde, em seu nível mais amplo e pleno, especialmente em meio à pandemia, não basta apenas expandir leitos hospitalares com respiradores e de unidades de terapia intensiva (UTI), é importante que se reorganize toda a estrutura das redes de atenção à saúde provendo novas tecnologias e cuidando também dos profissionais de saúde.

Palavras-chaves: Atenção Primária à Saúde, Infecções por coronavírus

\section{Covid-19 in Primary Health Care: another challenge}

\section{ABSTRACT}


In 2020 the world had a new experience that society has not experienced for a long time, an unprecedented pandemic. In March of that year, the World Health Organization (WHO) declared that the disease caused by the new corona virus (Sars-Cov2), COVID19, was present in several parts of the world. Faced with this scenario, and the absence of treatments for this disease, governments adopted drastic measures to face this virus, among them, social distancing strategies, such as lockdown, to contain the speed of dissemination of this agent, which caused profound changes in society. Despite the great potential for transmission, about $80 \%$ of cases are considered mild and do not use specialized services and are assisted by primary services. However, most countries used the strengthening of hospital levels as a strategy to combat the disease. In view of this paradox, it is important to reflect that for a health system to play its role of providing health, at its broadest and fullest level, especially in the midst of the pandemic, it is not enough to just expand hospital beds with respirators and intensive care units (ICU) ), it is important to reorganize the entire structure of health care networks, providing new technologies and also taking care of health professionals.

Key words: Primary Health Care, Coronavirus Infections.

\section{INTRODUÇÃO}

Em 2020 o mundo teve uma nova experiência há muito não vivida pela sociedade, uma pandemia sem precedentes. Em março desse ano a Organização Mundial de Saúde (OMS) declarou que a doença causada pelo novo corona vírus (Sars-Cov2), a COVID19, estava presente em várias partes do mundo. ${ }^{1}$ Até dezembro de 2020 haviam sido registrados mais de 82 milhões de casos com cerca de 1,8 milhões de mortes, sendo os Estados Unidos, Índia, Brasil, Rússia e França os países mais afetados ${ }^{2}$. No Brasil, foram registrados até dezembro de 2020 cerca de 7,6 milhões de pessoas contaminadas com mais de 193 mil óbitos em decorrência da COVID-19. ${ }^{3}$

Diante desse cenário, e da ausência de tratamentos para essa doença, os governos adotaram medidas drásticas para o enfrentamento deste vírus, dentre elas, estratégias de distanciamento social, como o lockdown, para conter a velocidade de disseminação deste agente, o que causou profundas mudanças na sociedade e teve impacto em aspectos sociais, econômicos, políticos e culturais ${ }^{4}$. 
A maioria dos países utilizou, como estratégia de combate à doença, o fortalecimento dos níveis hospitalares de atendimento, priorizando os casos mais graves, inclusive o Brasil. ${ }^{4,5}$. Contudo, apesar do grande potencial de transmissão, cerca de $80 \%$ dos casos são considerados leves e não utilizam estes serviços sendo assistidos pelos serviços primários, além dos casos moderados, que em grande parte, também buscam atendimento nos serviços primários de saúde. ${ }^{6}$

O Sistema Único de Saúde (SUS) brasileiro tem na Atenção Primária à Saúde (APS) sua porta principal de acesso e de comunicação com as redes de atenção à saúde (RAS). ${ }^{7}$ Este é o nível mais capilarizado e de maior contato com a população entendendo as particularidades dos territórios e, portanto, com grande capacidade de intervenção no cuidado da pandemia aplicando práticas de avaliação, tratamento, acompanhamento e monitoramento.

Diante deste paradoxo, é importante refletir que para um sistema de saúde desempenhar seu papel de prover saúde, em seu nível mais amplo e pleno, especialmente em meio à pandemia, não basta apenas expandir leitos hospitalares com respiradores e de unidades de terapia intensiva (UTI), é importante que se reorganize toda a estrutura da RAS redefinindo papeis dos pontos de apoio e acesso ao SUS, provendo novas tecnologias e cuidando também dos profissionais de saúde, considerando inclusive a saúde mental, sem perder o foco nos agravos rotineiros dos níveis de atenção. ${ }^{5}$

\section{A APS e o desafio da COVID-19}

Em relação à APS, embora não exerça um papel que impacte diretamente sobre a letalidade da doença, em condições adequadas e com pessoas capacitadas, possibilita a diminuição da incidência da COVID-19 em sua população com ações de redução da disseminação da infecção. Além disso, tem capacidade de apoiar as comunidades durante 
o distanciamento social, de acompanhar os casos leves em isolamento domiciliar, de identificar e manejar situações de vulnerabilidade e de garantir o acesso a cuidados de saúde e o encaminhamento nas fases mais críticas da doença mantendo os cuidados básicos dos demais agravos de saúde como hipertensão, diabetes e obesidade que são fatores de risco para a COVID-19. 6,8

Para isso, as atividades de rotina da APS como vacinação, consultas agendadas, pré-natal, acompanhamento dos grupos de riscos e de doenças crônicas, devem ser mantidas com as adequações necessárias. Essas adequações devem garantir a saúde tanto da população quanto dos profissionais. ${ }^{9}$ Devem ser garantidos o fornecimento e uso de equipamentos de proteção individual (EPI) por todos os profissionais de saúde, atendimento em locais diferenciados para cada atividade e higienização constante das áreas. Devem evitar o contato social e aglomerações devendo ser utilizados, quando possível, trabalhos com agendamentos, além da utilização do atendimento por meio eletrônico, garantindo, assim, a segurança da população quanto à possibilidade de contágio por vírus na UBS. ${ }^{10}$ Logo, se faz necessária à adequação da estrutura das UBS com rede de internet e telefônica adequadas e de equipamentos com câmeras e microfones. Também podem ser consideradas a criação de áreas específicas para atendimento aos casos inerentes à COVID-19 caso a Unidade Básica de Saúde (UBS) tenha essa capacidade.

A participação dos Agentes Comunitários de Saúde (ACS) também tem destaque neste processo de adaptação. Por ser o elo entre a comunidade e os serviços de saúde na APS, auxiliam com maior permeabilidade e aceitação das medidas adotadas pelos governos por parte da população e da comunidade no território. ${ }^{11}$ Este fato é atribuído à capilaridade deste profissional e sua capacidade de reconhecer as demandas e peculiaridades do seu território e de desenvolver papel fundamental no monitoramento e 
vigilância dos casos. Os ACS têm de desenvolver atividades de consciência, engajamento e sensibilização da comunidade sobre aspectos da doença, combate a estigmas e notícias falsas e rastreamento de contatos. ${ }^{11}$

A comunicação com os demais níveis de atenção é de suma importância para que a coordenação do cuidado, atribuição da APS, seja exercida, especialmente diante da pandemia. Para isso, os sistemas de informação e regulação de pacientes precisam ser interligados entre esses níveis. ${ }^{12}$ Quando essa comunicação possui algum tipo de ruído, o cuidado fica prejudicado e sem coesão. Um exemplo é o Distrito Federal onde, atualmente, são utilizados sistemas distintos de registro de informações sendo um da atenção primária, dois da atenção secundária e terciária e um de regulação e esses não são interligados. Logo, os níveis de atenção não conseguem se comunicar plenamente o que tem dificultado a longitudinalidade e a integralidade do cuidado. Além disso é importante que protocolos de triagem e classificação de risco, encaminhamentos e tratamentos sejam desenvolvidos e que considerem todos os níveis de atenção. ${ }^{12}$

Além dos fatores técnicos inerentes à pandemia, um outro desafio é apresentado à APS e que pode por abaixo os esforços para reorganização das estruturas dos serviços de saúde, um novo modo de pensar a APS e um novo modelo de financiamento por parte do Ministério da Saúde (MS) que pode romper com a universalidade do SUS. ${ }^{13}$ A PortariaMS 2979, de 12 de novembro de 2019 substituiu o piso de Atenção Básica fixo e o variável para incentivo às equipes saúde da família (eSF) ao Núcleo Ampliado em Saúde da Família e Atenção Básica (NASF-AB) por um pagamento por capitação ponderada, calculado pelo número de pessoas cadastradas a equipes. ${ }^{14} \mathrm{Na}$ prática, este novo modelo deixa de financiar a APS por meio de implantação de eSF e NASF-AB e passa a priorizar somente os pacientes cadastrados. Se considerarmos que a cobertura de APS no país sempre foi abaixo de $100 \%$ fatalmente haverá mais sub financiamento. ${ }^{13}$ 


\section{CONSIDERAÇÕES FINAIS}

Ainda que mudanças de fluxos e rotinas de um sistema de saúde possam parecer complexos, investir somente em infraestrutura hospitalar de respiradores e leitos de UTI não é o indicado para combate essa nova pandemia. A capacidade dos sistemas em salvar vidas dependerá de uma real articulação entre os níveis de atenção à saúde, garantindo acesso aos leitos, mas também na manutenção dos diversos atendimentos, no monitoramento dos casos e na vigilância. E neste sentido, a APS tem papel fundamental no combate a maioria dos casos de COVID-19 e na manutenção, manejo e vigilância dos demais agravos como hipertensão, diabetes, obesidade e demais transtornos de ordem mental como depressão e ansiedade. Por isso, faz-se necessário reconhecer a importância e a necessidade por mais recursos para que o sistema trabalhe positivamente frente às crises.

\section{REFERÊNCIAS}

1. WHO. Who director generals opening remarks at the media briefing on-covid-19 [Internet]. Available from: https://www.who.int/director-general/speeches/detail/whodirector-general-s-opening-remarks-at-the-media-briefing-on-covid-19---11-march2020

2. University Johns Hopkins. COVID-19 Dashboard by the Center for Systems Science and Engineering (CSSE) at Johns Hopkins University (JHU) [Internet]. Available from: https://coronavirus.jhu.edu/map.html

3. Brasil. Ministério da Saúde. Coronavírus Brasil [Internet]. Available from: https://covid.saude.gov.br/

4. Garcia Alves MT. Reflexões sobre o papel da Atenção Primária à Saúde na pandemia de COVID-19. Rev Bras Med Família e Comunidade. 2020;15(42):2496. 
5. Guadalupe Medina M, Giovanella L, Bousquat A, Magalhães de Mendonça MH, Aquino R. Primary healthcare in times of COVID-19: what to do? Cad Saude Publica. 2020;36(8).

6. Sarti TD, Lazarini WS, Fontenelle LF, Almeida APSC. Qual o papel da Atenção Primária à Saúde diante da pandemia provocada pela COVID-19? Epidemiol e Serv saude Rev do Sist Unico Saude do Bras. 2020;29(2):e2020166.

7. Ministério da Saúde (Brasil). Portaria $n^{\circ} 2436$, de 21 de setembro de 2017. Aprova a Política Nacional de Atenção Básica. Diário Oficial da União. 22 set. 2017; Seção 1

8. PAHO. Recomendaciones para la Reorganización y Ampliación Progresiva de los Servicios de Salud para la Respuesta a la Pandemia de COVID-19. 2020;

9. Siqueira C, Soares A, Luiza C. Atenção primária à saúde em tempos de pandemia O mundo vivencia algo totalmente novo e incerto : a pandemia do Coronavírus. 2020;111.

10. Pan American Health Organization (PAHO). Nota tecnica. La adaptación del primer nivel de atención en el contexto de la pandemia covid-19: intervenciones, modalidades y ámbitos . Iris. 2020;19:23-7.

11. Maciel FBM, Dos Santos HLPC, Carneiro RA da S, de Souza EA, Prado NM de BL, Teixeira CF de S. Community health workers: Reflections on the health work process in covid-19 pandemic times. Cienc e Saude Coletiva. 2020;25:4185-95.

12. Daumas RP, Azevedo e Silva G, Tasca R, da Costa Leite I, Brasil P, Greco DB, et al. The role of primary care in the Brazilian healthcare system: Limits and possibilities for fighting COVID-19. Cad Saude Publica. 2020;36(6).

13. Giovanella L, Cassiano Mendes Franco, Almeida PF de. Política Nacional de Atenção Básica: para onde vamos? Cien Saude Colet [Internet]. 2020;25(4):1475-81. Available from: https://www.scielo.br/pdf/csc/v25n4/1413-8123-csc-25-04-1475.pdf 
14. Ministério da Saúde (Brasil). Portaria $\mathrm{n}^{\mathbf{o}}$ 2979, de 12 de novembro de 2019. Institui o Programa Previne Brasil. Diário Oficial da União. 13 nov. 2019; Seção 1 